\title{
Vulnerabilidade ao burnout entre médicos de hospital público do Recife
}

\author{
Vulnerability to burnout among physicians \\ at a public hospital in Recife
}

Raitza Araújo dos Santos Lima ${ }^{1}$

Ariani Impieri de Souza ${ }^{1}$

Renata Hirschle Galindo ${ }^{1}$

Katia Virginia de Oliveira Feliciano ${ }^{1}$

${ }^{1}$ Diretoria de Pesquisas, Instituto de Medicina Integral Professor Fernando Figueira.

Rua dos Coelhos 300, Boa Vista. 50070-550 Recife

PE.raitza05@yahoo.com.br

\begin{abstract}
This study identified factors associated with burnout among physicians at a public hospital in Recife, Brazil. A self-administered questionnaire (socio-demographic characteristics, working conditions and Maslach Burnout Inventory) was completed by 158 physicians (92.4\%). Burnout was defined by a superposition of high scores in emotional exhaustion (EE) and depersonalization (DP) and low scores on personal accomplishment at work (PA). Chi-square and Fisher's exact test were used in the analysis and $5.1 \%$ had burnout. Female physicians were predominant in the sample (83.5\%) especially those for longer than ten years in the profession (81.6\%). High levels were found in EE (61.4\%) and DP (36.7\%) and low levels in PA (13.3\%). There was an association between: high EE and "often/always" working very fast and "never/rarely" having enough time for tasks; high level of DP and working ten years in the profession and "often/ always" doing tasks very fast; low level of PA and being female and "never/rarely" having enough time for tasks. Burnout and "often/always" working very quickly, "never/sometimes" having enough time for tasks, being male and having no expectation of professional growth. For $37.3 \%$, two of the three dimensions indicate a high propensity to burnout, making transformation in working conditions a priority.
\end{abstract}

Key words Professional burnout, Physicians, Job satisfaction
Resumo Identificou-se o burnout e fatores associados entre médicos de hospital público do Recife, Brasil, obtendo resposta de 158 profissionais (92,4\% do total) para questionário autoaplicável (aspectos sociodemográficos, laborais e Maslach Burnout Inventory). Definiu-se burnoutpela sobreposição de alta exaustão emocional (EE) e despersonalização (DP) e baixa realização profissional (RP). Aplicou-se qui-quadrado e teste exato de Fisher. Predominaram sexo feminino (83,5\%) e tempo de profissão acima de 10 anos $(81,6 \%)$. Constataram-se altos níveis de EE $(61,4 \%)$ e DP $(36,7 \%)$ e baixo nível de RP (13,3\%), estando 5,1\% com burnout. Mostraram associação: alto nível de EE e realizar "frequentemente/sempre" tarefas com muita rapidez e "nunca/às vezes" ter tempo suficiente; alto nível de DP e ter até dez anos de profissão e efetuar "frequentemente/sempre" tarefas com muita rapidez; baixo nivel de RP e gênero feminino e "nunca/às vezes" ter tempo suficiente; burnout e executar "frequentementel sempre" tarefas com muita rapidez, "nunca/às vezes" dispor de tempo suficiente, ser do gênero masculino e não ter expectativa de ascensão profissional. Para 37,3\% duas das três dimensões indicavam alta propensão à síndrome. O burnout institui-se entre médicos, tornando premente a transformação das condições de trabalho.

Palavras-chave Esgotamento profissional, Médicos, Satisfação no emprego 


\section{Introdução}

O burnout é uma resposta ao estresse laboral, percebido quando as estratégias de enfrentamento do estresse mostram-se ineficazes ${ }^{1,2}$. Conforme Tamayo \& Tróccoli ${ }^{1}$, o conceito de referência é o de Maslach e Jackson: a síndrome resulta de um processo que envolve a superposição de: (1) alta exaustão emocional (EE): perda ou desgaste dos recursos emocionais com sentimentos de esgotamento e tensão; (2) alta despersonalização (DP): distanciamento emocional contraproducente frente aos pacientes, colegas e organização; (3) baixa realização pessoal no trabalho (RP): tendência à autoavaliação negativa, com declínio no sentimento de competência.

Esta síndrome acomete quem trabalha de modo contínuo sob condições precárias, mas os profissionais de saúde são particularmente vulneráveis pela persistente tensão emocional advinda da responsabilidade de cuidar das pesso$\mathrm{as}^{1,2}$. Estudos que contemplam, ao mesmo tempo, distintas categorias de profissionais de saúde encontram maiores níveis entre médicos tanto da propensão à síndrome quanto da ocorrência de burnout $t^{3-11}$. A prática médica tem sido submetida à crescente pressão externa, o que contraria as expectativas de autonomia e dignidade no trabalho, para garantir adesão técnica à normatização de condutas e procedimentos e alcançar maior produtividade. A desvalorização social é percebida no desrespeito da população com a possibilidade recorrente da violência nos serviços e até mesmo de indiciamento judicial ${ }^{12}$.

No cotidiano do trabalho coexistem outros estressores que atuam como condicionantes do burnout, abrangendo aspectos individuais (idade, sexo, tempo de profissão, centralidade do trabalho, rede de apoio social) e organizacionais (sobrecarga, riscos e perigos, conflitos interpessoais, desempenho dos papéis, capacitação, participação na decisão, recompensas, suporte informacional e social no trabalho ${ }^{1,2,4}$. Apesar dos múltiplos elementos envolvidos, o burnout é fortemente associado ao suporte organizacional percebido, que representa um dos mais importantes preditores da EE, fator central da síndro$\mathrm{me}^{3,7,13}$. A organização tanto é considerada como interveniente entre as variáveis do contexto de trabalho e das características individuais dos trabalhadores, como mediadora entre o estresse percebido e suas consequências ${ }^{13}$.

Autores identificam a satisfação no trabalho como um fator de proteção contra o burnout $t^{3,7,14,15}$. As correlações entre estresse, satisfação e burnout reiteram a relevância dos fatores organizacionais em detrimento dos fatores pessoais ${ }^{7,14}$. Nas tentativas de enfrentamento das pressões geradoras do estresse laboral crônico são reconhecidas as limitações dos esforços cognitivos e comportamentais para administrar (reduzir ou tolerar) as demandas que surgem da interação com o ambiente. A busca de soluções pessoais para os problemas do trabalho favorece a continuidade de condições propicias à síndrome ${ }^{15,16}$. Na promoção da saúde laboral e na prevenção do burnout, a ênfase deve recair sobre os processos organizacionais de melhor suporte ao trabalho ${ }^{1,13}$.

São diversificados os efeitos do burnout sobre a saúde: hipertensão arterial, cefaleia, insônia, mialgia, artralgia, ansiedade, irritabilidade, desmotivação, desconcentração, entre outros; e o trabalho: absenteísmo, rotatividade, diminuição da produtividade e qualidade da assistência $^{1,2}$. É essencial aproximar-se à interação entre elementos dos contextos de trabalho, percepções e atitudes dos profissionais, visando contribuir para aumentar a qualidade do trabalho sem diminuir a qualidade de vida do trabalhador. Por isso, a relevância de um estudo onde se identifica a vulnerabilidade de médicos do sistema público de saúde ao burnout, estabelecendo a frequência da síndrome e das suas três dimensões, considerando alguns fatores sociodemográficos e das condições do trabalho que lhes são associados.

\section{Métodos}

Estudo descritivo de corte transversal, censitário, realizado de outubro a novembro de 2009 , em Recife, Brasil, num hospital público de nível terciário, que atua nas áreas de assistência, ensino e pesquisa. A população do estudo foi constituída por médicos do quadro funcional, contratados segundo regimento da Consolidação das Leis do Trabalho - CLT, com carga horária que variava entre 20 e 40 horas semanais e atividades desenvolvidas na assistência ambulatorial, hospitalar e urgência-emergência de Pediatria e Tocoginecologia. A partir de uma listagem fornecida pelo serviço, atualizada junto aos setores envolvidos, todos os 171 médicos que atendiam aos critérios de inclusão foram convidados a participar. Após serem informados sobre a pesquisa e assinarem o termo de consentimento livre e esclarecido, receberam o questionário autoaplicável e anônimo, agendando a data da devolução com a pesquisadora de campo. Destes, 158 ( $92,4 \%$ do total) devolveram o questionário.

O questionário contemplava duas partes: (1) aspectos sociodemográficos, formação profissi- 
onal, condições e recompensas do trabalho; (2) Maslach Burnout Inventory - MBI, conformado por escala Likert com 22 questões sobre as dimensões do burnout: nove avaliaram a EE, cinco a DP e oito a RP. O MBI foi traduzido para o português e validado em 1995, obtendo um alfa de Cronbachde 0,86 na subescala de EE, 0,69 em $\mathrm{DP}$ e $0,76 \mathrm{em} \mathrm{RP}{ }^{17}$. A cada uma das questões do MBI foram atribuídos graus de intensidade crescente: 1 (nunca), 2 (algumas vezes por ano), 3 (uma vez por mês), 4 (algumas vezes por mês), 5 (uma vez por semana), 6 (algumas vezes por semanas) e 7 (todos os dias). Realizou-se estudo piloto para proceder às adequações necessárias à primeira parte do questionário.

O programa Epi Info 6.04d foi utilizado na análise estatística dos dados. Em cada subescala do MBI a classificação obedeceu aos critérios de Maslach, para exaustão emocional: alto nível igual ou maior do que 27; nível médio - entre 19 e 26; e nível baixo - igual ou menor do que 18 . Para despersonalização: alto nível - igual ou maior do que 13; nível médio - entre sete e 12; e nível baixo - igual ou menor do que seis. Para realização pessoal: alto nível - igual ou maior do que 40; nível médio - entre 34 e 39; e nível baixo igual ou menor do que 33. A superposição de pontuações altas em EE e DP e pontuação baixa em RP indicam a ocorrência de burnout $t^{1,2}$.

$\mathrm{Na}$ análise, estabeleceu-se a associação entre as variáveis sociodemográficas, da formação profissional e do trabalho e a frequência do burnout e de cada uma das três dimensões. Diferenças significativas foram avaliadas usando o qui-quadrado e o teste exato de Fisher, quando necessário, com um nível de significância de 5\%. O termo "tendências" foi utilizado para descrever resultados nos quais se delineavam diferenças com significância estatística entre 0,05 e 0,10. O projeto foi aprovado pelo Comitê de Ética em Pesquisa do Instituto de Medicina Integral Prof. Fernando Figueira (IMIP).

\section{Resultados}

Na população estudada predominou o gênero feminino (83,5\%), com mediana de 37,5 anos de idade (intervalo interquartil de 32 a 46 anos) e $70,3 \%$ viviam em união civil estável. Ao redor de $81,6 \%$ tinham 11 e mais anos de profissão (mediana de 12 anos e intervalo interquartil de sete a 22 anos); mediana do tempo de trabalho no hospital onde foi desenvolvido o estudo de 7,5 anos (intervalo interquartil de três a 18 anos); 62,6\% eram pediatras e $82,9 \%$ especialistas na área de atuação. Proporção de 71,5\% estava vinculada a três ou mais serviços. Desenvolviam atividades na assistência hospitalar (82,9\%), assistência ambulatorial $(79,7 \%)$, ensino em graduação (55,7\%), ensino em pós-graduação $(35,4 \%)$ e pesquisa $(27,2 \%)$. Em torno de $72,8 \%$ trabalhavam como plantonistas.

Quando examinadas as questões das subescalas do MBI, no concernente à $\mathrm{EE}$, os médicos sentiam todos os dias $(18,4 \%)$ e algumas vezes na semana $(41,1 \%)$ que estavam esgotados ao terminar o trabalho. Todos os dias $(25,9 \%)$ e algumas vezes na semana $(21,5 \%)$ que trabalhavam demais. Algumas vezes na semana ficavam esgotados pela manhã ao pensar no trabalho $(27,2 \%)$. Uma vez ao mês sentiam-se decepcionados com o trabalho (32,9\%). Algumas vezes ao ano frustrados com o trabalho $(44,3 \%)$, no limite de suas possibilidades $(40,5 \%)$ e estressados por trabalhar com pessoas $(34,8 \%)$ (Tabela 1$)$.

Em relação à DP, os médicos sentiam todos os dias $(5,1 \%)$ e algumas vezes na semana (16,5\%) que eram culpabilizados pelos pacientes. Todos os dias $(8,2 \%)$, algumas vezes na semana $(11,4 \%)$, uma vez ao mês $(19,6 \%)$ e algumas vezes ao ano $(31,0 \%)$ que se tornaram mais duros com as pessoas. Todos os dias $(8,2 \%)$, algumas vezes na semana $(7,6 \%)$, uma vez ao mês $(15,8 \%)$ e algumas vezes ao ano $(33,5 \%)$ que estavam se enrijecendo emocionalmente. Uma vez ao mês $(13,3 \%)$ e algumas vezes ao ano $(20,3 \%)$ que tratavam as pessoas como objetos impessoais. Ao redor de $86,7 \%$ nunca deixaram de se importar e $60,1 \%$ nunca tratavam os pacientes como objetos impessoais (Tabela 1).

Quanto à RP, os médicos algumas vezes ao ano $(10,1 \%)$ e uma vez ao mês $(21,5 \%)$ sentiamse vigorosos no trabalho. Uma vez ao mês sentiam-se estimulados para trabalhar com pessoas $(17,1 \%)$, obtinham coisas valiosas no trabalho $(16,5 \%)$ e manejavam os problemas emocionais com calma $(14,6 \%)$. Todos os dias atendiam facilmente às pessoas $(70,3 \%)$, tratavam com eficiência os problemas das pessoas $(55,1 \%)$, criavam um clima agradável no trabalho $(54,4 \%)$ e exerciam influência positiva na vida das pessoas $(51,3 \%)$ (Tabela 1$)$.

Desses profissionais, $61,4 \%$ apresentavam alto nível de EE e 36,7\% de DP, estando 13,3\% com baixo nível de RP. Em 25,3\% e 47,5\% foram constatados níveis médios de, respectivamente, EE e DP, enquanto $81,0 \%$ manifestaram alto nível de RP.

Ser especialista na área de atuação $(\mathrm{p}<0,001)$ estava associado com alto nível de EE. Um percentual significativamente maior daqueles com até 10 anos de profissão $(\mathrm{p}=0,004)$ apresentava 
nível alto de DP. Um baixo nível de RP predominou de maneira estatisticamente significante no gênero feminino $(p=0,016)$. Observou-se tendência à baixa RP entre os médicos que tinham carga horária semanal de trabalho igual ou maior do que 41 horas $(\mathrm{p}=0,050)$ (Tabela 2$)$.

Uma proporção significativamente maior dos profissionais que "nunca/às vezes" tinham tempo suficiente para cumprir as tarefas $(\mathrm{p}=0,013) \mathrm{e}$ "frequentemente/sempre" realizavam suas tarefas com muita rapidez $(\mathrm{p}=0,002)$ estava com alto nível de EE. Existiu tendência a um nível alto de EE entre aqueles que acumulavam funções diferentes no mesmo serviço $(p=0,057)$. Um alto nível de DP encontrava-se associado a realizar "frequentemente/sempre" suas tarefas com muita rapidez ( $\mathrm{p}=$ 0,022 ), constituindo-se como uma tendência quando "nunca/às vezes" dispunham de tempo suficiente para cumprir as tarefas $(p=0,051)$. Uma baixa RP prevaleceu com significância estatística entre aqueles que "nunca/às vezes" contavam com tempo suficiente $(\mathrm{p}=0,043)$. Em $69,0 \%$ dos médicos pelo menos uma das três dimensões e em $37,3 \%$ pelo menos duas das três dimensões indicavam alta propensão ao burnout (Tabela 3).

Um percentual de $5,1 \%$ estava com burnout. Realizar "frequentemente/sempre" suas tarefas com muita rapidez $(p=0,011)$, "nunca/às vezes" dispor de tempo suficiente para cumprir as tarefas $(p=0,018)$, pertencer ao gênero masculino ( $p$ $=0,026)$ e não ter expectativa de ascensão profissional $(\mathrm{p}=0,048)$ estava associado ao burnout.

\section{Discussão}

Neste estudo, a baixa frequência de burnout $(5,1 \%)$ resulta, ao menos em parte, da adoção dos critérios de Maslach, referidos por vários autores $^{1,2}$, que são mais rigorosos por contemplar as inter-relações entre as três dimensões da síndrome. Utilizando este critério, Grau et al. comprovam prevalência de burnout entre $2,5 \% \mathrm{e}$ $5,9 \%$ em médicos de distintas especialidades de países hispano-americanos. No Brasil, Tucunduva et al. ${ }^{8}$ encontram $3,0 \%$ dos cancerologistas

Tabela 1. Percentual da frequência relativa de cada item do MaslachBurnoutInventory (MBI), dentro da correspondente dimensão, para os médicos de serviço de referência do Recife, Pernambuco, Brasil, 2009

\begin{tabular}{|c|c|c|c|c|c|c|c|}
\hline \multirow{2}{*}{$\begin{array}{l}\text { Dimensões } \\
\text { Itens }\end{array}$} & \multicolumn{7}{|c|}{ Pontuações (\%) (n=158) } \\
\hline & 1 & 2 & 3 & 4 & 5 & 6 & 7 \\
\hline \multicolumn{8}{|l|}{ Exaustão emocional } \\
\hline Sentir-se decepcionado com o trabalho & 8,2 & 36,7 & 32,9 & 7,0 & 4,4 & 9,5 & 1,3 \\
\hline Sentir-se esgotado após o término do trabalho & 2,5 & 8,2 & 21,5 & - & 8,2 & 41,1 & 18,4 \\
\hline Sentir-se esgotado pela manhã ao pensar no trabalho & 10,1 & 22,8 & 25,9 & 3,2 & 4,4 & 27,2 & 6,3 \\
\hline Sentir-se cansado ao trabalhar todo dia com pessoas & 25,9 & 32,9 & 20,3 & 3,2 & 2,5 & 10,8 & 4,4 \\
\hline Sentir que o trabalho está lhe desgastando & 5,1 & 28,5 & 27,2 & - & 3,8 & 23,4 & 12,0 \\
\hline Sentir-se frustrado com o trabalho & 19,0 & 44,3 & 20,3 & 3,2 & 2,5 & 7,6 & 3,2 \\
\hline Sentir que está trabalhando demais & 1,9 & 19,6 & 24,7 & 0,6 & 5,7 & 21,5 & 25,9 \\
\hline Sentir que trabalhar com pessoas é estressante & 19,6 & 34,8 & 22,2 & 3,2 & 1,3 & 14,6 & 4,4 \\
\hline Sentir-se no limite de suas possibilidades & 10,8 & 40,5 & 17,7 & 5,1 & 3,8 & 15,2 & 7,0 \\
\hline \multicolumn{8}{|l|}{ Despersonalização } \\
\hline Tratar as pessoas como objetos impessoais & 60,1 & 20,3 & 13,3 & 0,6 & 1,3 & 2,5 & 1,9 \\
\hline Tornou-se mais duro com as pessoas & 24,7 & 31,0 & 19,6 & 1,3 & 3,8 & 11,4 & 8,2 \\
\hline O trabalho esteja o enrijecendo emocionalmente & 31,0 & 33,5 & 15,8 & 1,3 & 2,5 & 8,2 & 7,6 \\
\hline Não importar-se com as pessoas que atende & 86,7 & 8,9 & 2,5 & - & - & 1,9 & \\
\hline Os pacientes o culpam por seus problemas & 30,4 & 25,9 & 16,5 & 2,5 & 3,2 & 16,5 & 5,1 \\
\hline \multicolumn{8}{|l|}{ Baixa realização profissional } \\
\hline Atende facilmente às pessoas & 0,6 & 2,5 & 3,2 & - & 1,3 & 22,2 & 70,3 \\
\hline Trata com eficiência os problemas das pessoas & 1,3 & 1,9 & 8,2 & 0,6 & 2,5 & 30,4 & 55,1 \\
\hline Exerce influência positiva na vida das pessoas & - & 1,9 & 11,4 & - & 3,8 & 31,6 & 51,3 \\
\hline Sentir-se vigoroso no trabalho & 3,8 & 10,1 & 21,5 & 0,6 & 3,2 & 34,2 & 26,6 \\
\hline Cria um clima agradável no trabalho & 0,6 & 3,8 & 10,1 & 2,5 & 1,9 & 26,6 & 54,4 \\
\hline Sentir-se estimulado após trabalhar com pessoas & 2,5 & 4,4 & 17,1 & 1,3 & 3,8 & 36,1 & 34,8 \\
\hline Consegue coisas valiosas no trabalho & 1,9 & 5,7 & 16,5 & 0,6 & 3,8 & 30,4 & 41,1 \\
\hline Manobra os problemas emocionais com calma & 0,6 & 6,3 & 14,6 & 0,6 & 2,5 & 34,8 & 40,5 \\
\hline
\end{tabular}

1. Nunca; 2. Algumas vezes por ano; 3. Uma vez por mês; 4. Algumas vezes por mês; 5 . Uma vez por semana; 6 . Algumas vezes por semana; 7. Todos os dias. 
e Barros et al. $.^{10} 7,4 \%$ dos médicos intensivistas, acometidos da síndrome. Em contrapartida, Grunfeld et al. ${ }^{3}$ desconsideram a multidimensionalidade do burnout que é diagnosticado quando da presença isolada de nível alto de EE ou DP, ou nível baixo em RP. Por este critério, 69,0\% na pesquisa atual; $63,3 \%$ na efetuada com intensivistas $^{10}$ e $52,3 \%$ com os cancerologistas ${ }^{8}$ estavam com burnout, pois apresentaram ao menos uma dimensão da síndrome em nível crítico.

Constatou-se proporção de médicos com alto nível de EE $(61,0 \%)$ e de DP $(36,7 \%)$ maior do

Tabela 2. Níveis das três dimensões do burnout, segundo gênero e características profissionais e do trabalho, entre médicos de serviço de referência do Recife, Pernambuco, Brasil, 2009

\begin{tabular}{|c|c|c|c|c|c|c|c|c|c|c|c|c|}
\hline \multirow{2}{*}{ Variáveis } & \multicolumn{4}{|c|}{ Exaustão emocional } & \multicolumn{4}{|c|}{ Despersonalização } & \multicolumn{4}{|c|}{ Realização profissional } \\
\hline & $\begin{array}{c}\text { Baixo } \\
\%\end{array}$ & $\begin{array}{c}\text { Médio } \\
\%\end{array}$ & $\begin{array}{c}\text { Alto } \\
\%\end{array}$ & $p$ & $\begin{array}{c}\text { Baixo } \\
\%\end{array}$ & $\begin{array}{c}\text { Médio } \\
\%\end{array}$ & $\begin{array}{c}\text { Alto } \\
\%\end{array}$ & $p$ & $\begin{array}{c}\text { Baixo } \\
\%\end{array}$ & $\begin{array}{c}\text { Médio } \\
\%\end{array}$ & $\begin{array}{c}\text { Alto } \\
\%\end{array}$ & $p$ \\
\hline \multicolumn{13}{|l|}{ Gênero } \\
\hline Masculino $(\mathrm{n}=26)$ & 3,8 & 23,1 & 73,1 & 0,241 & 7,8 & 46,1 & 46,1 & 0,355 & 30,8 & 3,8 & 65,4 & 0,016 \\
\hline Feminino $(\mathrm{n}=132)$ & 15,2 & 25,8 & 59,0 & & 17,4 & 47,8 & 34,8 & & 9,8 & 6,1 & 84,1 & \\
\hline \multicolumn{13}{|l|}{ Tempo de profissão (anos) } \\
\hline $1-10(\mathrm{n}=29)$ & 3,4 & 27,6 & 69,0 & 0,224 & 3,4 & 34,5 & 62,1 & 0,004 & 13,8 & - & 86,2 & 0,341 \\
\hline$>11(\mathrm{n}=129)$ & 15,5 & 24,8 & 59,7 & & 18,6 & 50,4 & 31,0 & & 13,2 & 7,0 & 79,8 & \\
\hline \multicolumn{13}{|l|}{ Área de atuação } \\
\hline Pediatria $(\mathrm{n}=99)$ & 14,1 & 28,3 & 57,6 & 0,428 & 16,2 & 43,4 & 40,4 & 0,384 & 16,2 & 6,0 & 77,8 & 0,359 \\
\hline Ginecologia $(\mathrm{n}=59)$ & 11,9 & 20,3 & 67,8 & & 15,2 & 54,3 & 30,5 & & 8,5 & 5,1 & 86,4 & \\
\hline \multicolumn{13}{|c|}{ Especialista na área que atua } \\
\hline $\operatorname{Sim}(n=131)$ & 15,3 & 19,1 & 65,6 & 0,000 & 17,5 & 44,3 & 38,2 & 0,169 & 11,5 & 5,3 & 83,2 & 0,275 \\
\hline Não $(\mathrm{n}=27)$ & 3,7 & 55,6 & 40,4 & & 7,4 & 63,0 & 29,6 & & 22,2 & 7,4 & 70,4 & \\
\hline \multicolumn{13}{|c|}{ Carga horária semanal (horas) } \\
\hline$<40(\mathrm{n}=30)$ & 16,7 & 33,3 & 50,0 & 0,360 & 16,7 & 56,7 & 26,7 & 0,428 & 26,7 & 6,7 & 66,6 & 0,050 \\
\hline$>41(\mathrm{n}=128)$ & 12,5 & 23,4 & 64,1 & & 15,6 & 45,3 & 39,1 & & 10,2 & 5,5 & 84,4 & \\
\hline
\end{tabular}

Tabela 3. Níveis das três dimensões do burnout, segundo condições de trabalho e recompensas entre médicos de serviço de referência do Recife, Pernambuco, Brasil, 2009

\begin{tabular}{|c|c|c|c|c|c|c|c|c|c|c|c|c|}
\hline \multirow{2}{*}{ Variáveis } & \multicolumn{4}{|c|}{ Exaustão emocional } & \multicolumn{4}{|c|}{ Despersonalização } & \multicolumn{4}{|c|}{ Realização profissional } \\
\hline & $\begin{array}{c}\text { Baixo } \\
\%\end{array}$ & $\begin{array}{l}\text { Médio } \\
\%\end{array}$ & $\begin{array}{c}\text { Alto } \\
\%\end{array}$ & $p$ & $\begin{array}{l}\text { Baixo } \\
\%\end{array}$ & $\begin{array}{l}\text { Médio } \\
\%\end{array}$ & $\begin{array}{c}\text { Alto } \\
\%\end{array}$ & $p$ & $\begin{array}{c}\text { Baixo } \\
\%\end{array}$ & $\begin{array}{l}\text { Médio } \\
\%\end{array}$ & $\begin{array}{c}\text { Alto } \\
\%\end{array}$ & $p$ \\
\hline \multicolumn{13}{|c|}{ Tempo suficiente para cumprir tarefas } \\
\hline Nunca/Às vezes $(\mathrm{n}=53)$ & 3,8 & 20,8 & 75,4 & 0,013 & 9,4 & 41,5 & 26 & 0,051 & 22,6 & 3,8 & 73,6 & 0,043 \\
\hline Frequente/Sempre $(\mathrm{n}=105)$ & 18,1 & 27,6 & 54,3 & & 19,0 & 50,5 & 32 & & 8,6 & 6,7 & 84,8 & \\
\hline \multicolumn{13}{|c|}{$\begin{array}{l}\text { Frequência com que faz tarefas com } \\
\text { muita rapidez }\end{array}$} \\
\hline Nunca/Às vezes $(\mathrm{n}=66)$ & 19,7 & 34,8 & 45,5 & 0,002 & 19,7 & 56,1 & 16 & 0,022 & 10,6 & 7,6 & 81,8 & 0,515 \\
\hline Frequente/Sempre $(\mathrm{n}=92)$ & 8,7 & 18,5 & 72,8 & & 13,0 & 41,3 & 42 & & 15,2 & 4,3 & 80,5 & \\
\hline \multicolumn{13}{|l|}{$\begin{array}{l}\text { Acumula funções diferentes no } \\
\text { mesmo serviço }\end{array}$} \\
\hline $\operatorname{Sim}(\mathrm{n}=70)$ & 11,4 & 17,1 & 71,5 & 0,057 & 10,0 & 48,6 & 29 & 0,174 & 12,9 & 2,9 & 84,2 & 0,375 \\
\hline Não $(\mathrm{n}=88)$ & 14,8 & 31,8 & 53,4 & & 20,5 & 46,5 & 29 & & 13,6 & 8,0 & 78,4 & \\
\hline \multicolumn{13}{|l|}{$\begin{array}{l}\text { Salário compatível com esforço } \\
\text { empregado }\end{array}$} \\
\hline $\operatorname{Sim}(\mathrm{n}=21)$ & 23,8 & 33,3 & 42,9 & 0,136 & 23,8 & 47,6 & 6 & 0,493 & 14,2 & 4,8 & 81,0 & 0,973 \\
\hline Não (n = 137) & 11,7 & 24,1 & 64,2 & & 14,6 & 47,4 & 52 & & 13,2 & 5,8 & 81,0 & \\
\hline \multicolumn{13}{|c|}{ Possibilidade de ascensão profissional } \\
\hline $\operatorname{Sim}(\mathrm{n}=127)$ & 12,6 & 27,6 & 59,8 & 0,412 & 17,3 & 46,5 & 46 & 0,576 & 11,8 & 4,7 & 83,5 & 0,269 \\
\hline Não $(\mathrm{n}=31)$ & 16,1 & 16,1 & 67,8 & & 9,7 & 51,6 & 12 & & 19,3 & 9,7 & 71,0 & \\
\hline
\end{tabular}


que a observada por Grau et al. ${ }^{4}$ em hospitais da Catalunha (Espanha): 46,5\% de EE e 31,7\% de DP, bem como por Grunfeld et al. ${ }^{3}$ em Ontário (Canadá): 53,3\% com nível alto de EE e 22,1\% de DP. Os resultados de Barros et al. ${ }^{10}$ em Salvador (BA) mostram quantitativo menor de plantonistas de medicina intensiva com alta EE $(47,5 \%)$ e DP $(24,6 \%)$. Tucunduva et al. ${ }^{8}$ também identificam entre cancerologistas brasileiros um menor percentual de alto nível de EE (34,1\%), sendo igual a alta DP $(36,7 \%)$.

As respostas aos itens do MBI denotaram uma situação preocupante, sobretudo porque o burnout é um processo insidioso que se desenvolve ao longo do tempo ${ }^{1,2}$. A dimensão EE evidenciou uma forte e persistente percepção de estar submetido à carga excessiva de trabalho e à tensão dela resultante, a qual se manifestou como cansaço, desgaste e esgotamento crônico. A sobrecarga laboral é uma fonte persistente de estresse, sendo um dos principais preditores da EE que é considerada como etapa inicial e fator central do burnout $t^{3,6,13,18}$. Também despontavam decepção, frustração de expectativas e sensação de não dispor da energia requerida pelo seu trabalho.

No estudo atual, como em outros ${ }^{1,13,19,20}$, a insuficiência do tempo para efetuar tarefas e a necessidade de realizá-las com muita rapidez estavam estatisticamente associados com altos níveis de EE. A incorporação dos conceitos de produtividade, rendimento, custo-benefício, como parte da regulação do desempenho do médico, redimensiona a racionalidade do seu processo de trabalho que deixa de ser apenas técnica para ser também econômica. A produtividade é alcançada pela intensificação do ritmo de trabalho e as decisões que envolvem enorme responsabilidade são tomadas sob pressão do tempo, num contexto de limitado controle dos fatores intervenientes ${ }^{20}$.

A regulação de metas, atividades e meios do trabalho demonstra as relações de poder que afetam a dinâmica e os resultados institucionais. Assim, representa uma importante área de confronto que origina uma percepção mais negativa dos contextos de trabalho. Cecílio ${ }^{21}$, em experiência de gestão hospitalar, identifica que os médicos não aceitam o controle externo. Para Horwitz $^{12}$, as obrigações produtivas do trabalho médico levam à percepção de liberdade profissional diminuída, sendo sentidas frequentemente como alienantes.

A tendência para apresentar níveis altos de $\mathrm{EE}$, constatada quando os profissionais acumulavam funções diferentes num mesmo serviço, foi observada em outras pesquisas ${ }^{19,20}$. A polivalência provoca uma alta demanda de trabalho, já que aumenta a carga laboral e a pressão do tempo para efetuação das tarefas. Também acentua a incerteza entre as exigências das atividades e os conhecimentos e habilidades requeridos para concretizá-las. Essa ambiguidade no desempenho dos papéis torna sempre presente o temor do imprevisível no dia a dia do trabalho. Além disso, podem ocorrer conflitos advindos das expectativas dos múltiplos papéis a desempenhar (clínico, professor, pesquisador, gerente). A polivalência deixa mais premente a necessidade de recursos para atendimento das exigências excessivas da multiplicidade de atribuições ${ }^{19,20}$.

Apesar da grande proporção de médicos que conferiam importância às pessoas atendidas, a dimensão DP revelou o significativo comprometimento da relação profissional-paciente, um dos principais preditores do burnout ${ }^{22}$. A falta de reciprocidade com os pacientes e o distanciamento emocional contraproducente em que o paciente foi tratado com impessoalidade, são fortes indicativos de que o trabalho estava requerendo um enorme esforço por parte de parcela importante desses profissionais. O médico mantém intenso contato face a face, lida cotidianamente com o sofrimento e a morte de pacientes, apoiando aos familiares num momento crítico, além da frustração de não poder curar.

Um elemento que merece destaque na configuração do burnout é a percepção pelo profissional da falta de retorno dos beneficiários de seus serviços ${ }^{1}$. As restrições na expressão de satisfação, gratidão e respeito pelos pacientes, os quais podem compreender que cuidar é um dever dos médicos, reforçam o sentimento de estar sendo injustiçado e deterioram o vínculo profissionalpaciente. Estudos encontram correlação positiva significativa entre a percepção de falta de reciprocidade com os pacientes e as duas dimensões do burnout, EE e DP ${ }^{1,20,22}$

Os sentimentos e as atitudes negativas no trabalho característicos da DP também se fizeram presentes de modo significativamente maior entre os médicos que se sentiram pressionados a agir com muita rapidez, aparecendo como tendência quando o tempo era insuficiente. As obrigações produtivas levam os médicos a atender um número maior de pacientes, precisando fazer muito em pouco tempo, frequentemente sob condições inadequadas de trabalho e baixa participação nas decisões institucionais ${ }^{20,22}$. Autores apontam para o caráter recursivo da relação entre a pressão do tempo e o burnout que compromete cada vez mais a saúde do trabalhador ${ }^{18-20}$.

A associação estatística entre alto nível de DP e menor tempo de profissão pode decorrer de 
expectativas não concretizadas e da dificuldade para vislumbrar maiores possibilidades de melhoria nas condições laborais ${ }^{11,23}$. Aqueles com mais tempo de profissão sentem o cansaço e o desgaste, mas para manter o otimismo continuam esperando uma solução, talvez porque estejam mais complacentes ou extraiam aspectos positivos de experiências negativas. BenevidesPereira $^{23}$ lembra que aqueles mais antigos na profissão que estavam insatisfeitos com o trabalho e tiveram oportunidade de mudança, já podem ter seguido outros caminhos.

Convém atentar-se para dois aspectos relacionados à magnitude dos altos níveis de DP na presente pesquisa: (a) pode estar subdimensionada pela possível interferência da desejabilidade social nas respostas dadas aos itens dessa dimensão, pois os mesmos desafiam a imagem profissional do médico; (b) os resultados se referem a uma população com nítida predominância do gênero feminino que, considerando os modelos de socialização ainda hegemônicos, é condicionado para o cuidado ${ }^{23,24}$. Escamilla-Quintal et al. ${ }^{25}$ argumentam que a adoção de uma atitude fria, distante, em relação aos pacientes implicaria para as mulheres em ir de encontro às características que definem o seu papel de gênero, podendo aumentar a sua ansiedade e esgotamento.

Identificou-se nível alto de RP $(81,0 \%)$, superior aos 32,7\% encontrado por Grau et al. ${ }^{4}$ na Catalunha, aos $45,1 \%$ referido por Barros et al. ${ }^{10}$ e aos 76,6\% mencionado por Tucunduva et al. ${ }^{8}$. O baixo nível de RP foi significativamente maior entre profissionais do gênero feminino e com tempo insuficiente para efetuar o trabalho. A literatura é contraditória quanto à associação entre gênero e satisfação no trabalho que seria mais influenciada pelo suporte organizacional ${ }^{4,5,24}$. Contudo, Gil-Monte ${ }^{24}$ aponta a falta de reciprocidade percebida como um preditor significativo de RP entre as mulheres. Grau et al. ${ }^{5}$ encontram menor pontuação em RP entre as mulheres.

No que se refere à percepção de falta de reciprocidade entre instituição e profissionais cabe atentar-se, também, para o vínculo empregatício (embora este aspecto não tenha sido incluído na atual investigação), que pode gerar incerteza em relação ao futuro profissional, originando um forte sentimento de ser injustiçado, de falta de retribuição da organização pelo trabalho realizado. A insegurança quanto à manutenção do emprego é um fator relacionado à satisfação no trabalho que aumenta a vulnerabilidade ao burnout, em particular, na presença de desgaste emo- cional e desestímulo advindo da discrepância entre as condições de trabalho existentes e aquelas que deveriam existir ${ }^{13,20}$

Neste estudo, o burnout estava estatisticamente associado à pressão do tempo e à falta de expectativa de ascensão profissional. Diversos autores relacionam a síndrome com os obstáculos para ascender e obter reconhecimento de seu trabalho, reiterando a importância da percepção de suporte organizacional insuficiente sobre a saúde no trabalho ${ }^{13,23}$. Também se observou associação entre burnout e gênero masculino. Aspecto particularmente relevante dado ao elevado percentual de mulheres participantes, que poderia ter encoberto a diferença existente em função do gênero. Pesquisas desenvolvidas com professores têm mostrado maior vulnerabilidade do gênero masculino em comparação com o feminino, o que levou à suposição de que mulheres são mais flexíveis e mais abertas para lidar com as várias pressões presentes na profissão de ensi$\mathrm{no}^{26}$. Gil-Monte ${ }^{24}$ recomenda que as ações preventivas considerem os papéis atribuídos aos gêneros no processo de socialização.

Parcela importante dos médicos estava em "quase-burnout", pois pelo menos duas das três dimensões indicavam forte propensão à síndrome, denotando extrema vulnerabilidade. A alta $\mathrm{RP}$, certamente, atenuava as consequências da superposição de altos níveis de EE e DP, podendo justificar este estágio de transição em direção à síndrome. Estudos nacionais e internacionais identificam uma correlação negativa da satisfação no trabalho com a RP ${ }^{3,6,15}$. Visser et al. ${ }^{14}$ constatam o efeito protetor da satisfação no trabalho contra as consequências negativas do estresse ocupacional e a importância da condição de trabalho percebida no manejo de ambos: estresse ocupacional e satisfação no trabalho.

As estratégias desenvolvidas para responder às altas demandas do trabalho, tidas como excessivas para os recursos individuais, tanto podem favorecer como dificultar a ocorrência de burnout. É preocupante a utilização de estratégias de escape, facilitadoras da síndrome ${ }^{13,15}$, como tratamento frio e distanciamento emocional dos pacientes. A concepção do burnout como um problema coletivo e organizacional deixou mais nítido o caráter paliativo de uma intervenção que não esteja voltada às mudanças nas condições de trabalho ${ }^{1,13-15}$. Logo, na prevenção do burnout, é fundamental dar ênfase às transformações requeridas pelos aspectos situacionais próprios dos contextos laborais. 


\section{Colaboradores}

RAS Lima, AI Souza, RH Galindo e KVO Feliciano participaram igualmente de todas as etapas de elaboração do artigo.

\section{Referências}

1. Tamayo M, Tróccoli BT. Burnout no trabalho. In: Mendes AM, Borges LO, Ferreira MC, organizadores. Trabalho em transição, saúde em risco. Brasília: Editora Universidade de Brasília; 2002. p.45-63.

2. Ruiz CO, Rios FL. El burnout o síndrome de estar quemado en los profesionales sanitarios: revisión y perspectivas. Int J Clin Health Psychol. 2004; 4(1):137160.

3. Grunfeld E, Whelan TJ, Zitzelsberger L, Willan AR, Montesanto B, Evans WK. Cancer care workers in Ontario: prevalence of burnout, job stress and job satisfaction. JAMC 2002; 163(2):166-169.

4. Grau A, Suñer R, García MM. Desgaste profesional en el personal sanitario y su relación con los factores personales y ambientales. Gac Sanit 2005; 19(6):463-470.

5. Grau A, Flichtentrei D, Suñer R, Prats M, Braga F. Influencia de factores personales, profesionales y transnacionales em el síndrome de burnout en personal sanitário hispanoamericano y español (2007). Rev Esp Salud Públ 2009; 83(2):215-230.

6. Escribà-Agüir V, Artazcoz L, Pérez-Hoyos S. Efecto del ambiente psicosocial y de la satisfacción laboral en el síndrome de burnout en médicos especialistas. Gac Sanit 2008; 22(4):300-308.

7. Ozyrt A, Hayran O, Sur H. Predictors of burnout and job satisfaction among Turkish physicians. QJM 2006; 99(3):161-169.

8. Tucunduva LTCM, Garcia AP, Prudente FVB, Centofanti G, Souza CM, Monteiro TA, Vince FAH, Samano EST, Gonçalves MS, Del Giglio A. A síndrome da estafa profissional em médicos cancerologistas brasileiros. Rev Assoc Med Bras 2006; 52(2):108-112.

9. Glasberg J, Horiuti L, Novais MAB, Canavezzi AZ, Miranda VC, Chicoli FA, Gonçalves MS, Bensi CG, del Giglio A. Prevalence of the burnout syndrome among brazilian medical oncologists. Rev Assoc Med Bras 2007; 53(1):85-89.

10. Barros DS, Tironi MOS, Nascimento Sobrinho CL Neves FS, Bitencourt AGV, Almeida AM, Souza YG, Teles MS, Feitosa AIR, Mota ICC, França J, Borges LG, Lordão MBJ, Trindade MV, Almeida MBT, Marques Filho ES, Reis EJFB. Médicos plantonistas de unidade de terapia intensiva: perfil sócio-demográfico, condições de trabalho e fatores associados à síndrome de burnout. Rev bras. ter intensiva 2008; 20(3):235-240.

11. Feliciano KVO, Kovacs MH, Sarinho SW. Sentimentos de profissionais dos serviços de pronto-socorro pediátrico: reflexões sobre o burnout. Rev Bras Saude Mater Infant 2005; 5(3):319-328.

12. Horwitz N. El cambio de la práctica médica. Desafíos psicosociales para la profesión. Rev méd Chile 2004; 132(6):768-772.
13. Tamayo MR, Tróccoli BT. Exaustão emocional: relações com a percepção de suporte organizacional e com as estratégias de coping no trabalho. Estud Psicol (Natal) 2002; 7(1):37-46.

14. Visser MRM, Smets EMA, Oort FJ, Haes HCJM. Stress, satisfaction and burnout among Dutch medical specialists. CMAJ 2003; 168(3):271-275.

15. Rosa C, Carlotto MS. Síndrome de burnout e satisfação no trabalho em profissionais de uma instituição hospitalar. Rev SBPH 2005; 8(2):1-15.

16. Lemaire JB, Wallace JE. Not all coping strategies are created equal: a mixed methods study exploring physicians' self reported coping strategies. BMC Health Serv Res 2010; 10:208.

17. Lautert L. O desgaste profissional do enfermeiro [tese]. Salamanca: Faculdade de Psicologia, Universidade Pontifícia de Salamanca; 1995.

18. Leiter MP, Frank E, Matheso TJ. Demands, values, and burnout. Can Fam Physician 2009; 55(12):12241230.

19. Soratto L, Pinto RM. Burnout e carga mental no trabalho. In: Codo W, organizador. Educação: carinho e trabalho. 2a Edição. Petrópolis: Vozes; 2000. p. 282-292.

20. Castro FG, Zanelli JC. Síndrome de burnoute projeto de ser. Cad. psicol. Soc. trab 2007; 10(2):17-33.

21. Cecílio LCO. O desafio de qualificar o atendimento prestado pelos hospitais públicos. In: Merhy EE, Onocko R, organizadores. Agir em saúde: um desafio para o público. 2a Edição. São Paulo: Hucitec; 2002. p. 293-319.

22. Carlotto MS. A relação profissional-paciente e a síndrome de burnout. Encontro: Revista de Psicologia 2009; 12(17):7-20.

23. Benevides-Pereira AMT. As atividades de enfermagem em hospital: um fator de vulnerabilidade ao burnout. In: Benevides-Pereira AMT, organizador. Burnout: quando o trabalho ameaça o bem-estar do trabalhador. São Paulo: Casa do Psicólogo; 2002. p. 133-155.

24. Gil-Monte PR. Influencia del género sobre el proceso de desarrollo del síndrome de quemarse por el trabajo (burnout) en profesionales de enfermería. Psicol. estud. 2002; 7(1):3-10.

25. Escamilla-Quintal M, Rodríguez-Molina I, Peiró JM, Marco IT. El cinismo: una estrategia de afrontamiento diferencial en función del gênero. Psicothema 2008; 20(4):596-602.

26. Carlotto MS. A síndrome de burnout e o trabalho docente. Psicol estud 2002; 7(1):21-29.

Artigo apresentado em 05/09/2011

Aprovado em 09/10/2011

Versão final apresentada em 13/11/2011 